\section{Microscopic investigations as an aid in raw ham's ripening analysis}

Domenico Paludi, ${ }^{1}$

Giovanni Di Guardo, ${ }^{1}$

Alberto Olivastri, ${ }^{2}$ Antonio Zizzi, ${ }^{3}$

Corrado Rubini, ${ }^{3}$ Luca Maria Pennisi, ${ }^{1}$

Marina Baffoni, ${ }^{1}$ Anna Rita Festino, ${ }^{1}$

Adriana Ianieri, ${ }^{4}$ Alberto Vergara ${ }^{1}$

${ }^{1}$ Faculty of Veterinary Medicine, University of Teramo; ${ }^{2}$ Department of

Prevention, ASUR Marche, Ascoli

Piceno; ${ }^{3}$ Department of Biomedical

Sciences and Public Health, Section of

Pathologic Anatomy and Histopathology,

Polytechnic University of Marche,

Ancona; ${ }^{4}$ Department of Food Science,

University of Parma, Italy

\begin{abstract}
The raw ham's ripening process contributes to the development of numerous biochemical reactions, mainly affecting proteins and lipids and allowing to obtain an adequate texture and a characteristic flavor. This article reports the results of histologic investigations carried out on 5 different anatomic regions from raw hams manufactured in the Fermo Province, Marche Region, Central Italy. Raw ham specimens were collected at the 10 following time intervals throughout the ripening process: 1) "Time 0", when ripening was started, 2) one month, 3) three months, 4) four months, 5) eight months, 6) nine months, 7) twelve months, 8) eighteen months, 9) twentythree months and 10) twenty-eight months after the ripening process began, respectively. Different microscopic findings of variable extension and degree were observed, with the vast majority of them being interpreted as dehydration- and proteolysisrelated modifications. In conclusion, morpho-histological investigations may represent a valuable aid in raw ham's ripening analysis.
\end{abstract}

\section{Introduction}

Raw ham represents a "flagship product" within the highly variegated and world-renowned Italian food supply. Raw ham undergoes an ad hoc ripening process lasting no less than 12 months and characterized by several biochemical reactions, the proper occurrence and evolutionary dynamics of which are of crucial relevance for the final product's quality (Toldrá and
Flores, 1998). To the best of our knowledge and differently from what reported in a strictly "biochemical perspective" (Fritz and Greaser, 1991; Fritz et al., 1993; Toldrá and Aristoy, 1993; Toldrá and Flores, 1998; Gil et al., 1999; Larrea et al., 2006), there are very few studies addressing the light and/or ultrastructural microscopic features of this "flagship" swine meat product (Córdoba et al., 1994; Monin et al., 1997; Larrea et al., 2007a), with only one of them addressing the morphologic changes of the sarcoplasmal protein matrix during raw ham's ripening (Larrea et al., 2007b).

Based on these evidences, the aim of the present study was to analyze, by means of conventional light microscopy, the structural modifications of raw ham muscle tissue throughout the entire ripening process. Investigating raw ham's histomorphological and histochemical features may provide, in fact, additional support to the qualitative evaluation of this iconic product of the Italian food industry, which is routinely based upon visual inspection and olfactory analysis.

\section{Materials and Methods}

The 3 herein investigated raw hams, the fresh weights of which were $12.5 \mathrm{~kg}, 13.5$ $\mathrm{kg}$ and $14.5 \mathrm{~kg}$, respectively, originated from a hilly area of the Fermo Province, Marche Region, Central Italy, having been obtained from 3 regularly slaughtered, commercial hybrid pigs.

Hams were directly salted and placed in drying conditions (Toldrá and Flores, 1998). At the end of the ripening process, the final weights of the 3 raw hams under study - all of which derived from the right hind limbs of the 3 aforementioned animals - were, respectively, $9 \mathrm{Kg}$ (12.5 kg fresh weight), $9.2 \mathrm{Kg}$ (13.5 kg fresh weight) and $9.5 \mathrm{~kg}$ (14.5 kg fresh weight). These values were measured when the ripening stage of 28 months, coincident with the end of a "conventional" ripening process, was reached.

All of the hams were subjected to an ad hoc tissue sampling protocol, by collection of tissue specimens, which was carried out at the 10 following time intervals throughout the entire ripening process: 1 ) "Time 0 ", when ripening process was started; 2) One month after starting ripening process; 3) Three months after starting ripening process; 4) Four months after starting ripening process; 5) Eight months after starting ripening process; 6) Nine months after starting ripening process; 7) Twelve months after starting ripening process; 8) Eighteen months after starting ripening process; 9)
Correspondence: Domenico Paludi, University of Teramo, Faculty of Veterinary Medicine, Località Piano d'Accio, 64100 Teramo, Italy

E-mail: dpaludi@unite.it

Key words: Raw ham, ripening, morphological investigations, histology, histochemistry, light microscopy.

Contributions: the authors contributed equally. Conflict of interest: the authors declare no potential conflict of interest.

Funding: none.

Received for publication: 12 March 2019

Revision received: 24 May 2019

Accepted for publication: 30 May 2019

This work is licensed under a Creative Commons Attribution-NonCommercial 4.0 International License (CC BY-NC 4.0).

CCopyright D. Paludi et al., 2019

Licensee PAGEPress, Italy

Italian Journal of Food Safety 2019; 8:8166 doi:10.4081/ijfs.2019.8166

Twenty-three months after starting ripening process; 10) Twenty-eight months after starting ripening process.

During each of the aforementioned sampling operations, 3 tissue specimens were collected from each of the 5 herein specified anatomic regions: 1) surface of vastus medialis muscle; 2) upper aspect of vastus lateralis muscle; 3) thigh adductor muscle; 4) semitendinous muscle; 5) semimembranous muscle. Each muscle tissue specimen ranged in size from $1.5 \mathrm{~cm}$ to 2.5 $\mathrm{cm}$.

All samples were fixed in $10 \%$ neutral buffered formalin, embedded in paraffin and cut into 5 micron-thick sections. Out of the 4 sections obtained from each skeletal muscle tissue specimen under study, 2 were routinely stained with hematoxylin and eosin (HE), while the remaining 2 sections were histochemically stained with PicroMallory (PM) and Periodic Acid-Schiff (PAS), respectively, to be finally observed under a light microscope.

\section{Results}

The results of the histological examinations performed on the raw ham samples obtained from the 3 herein investigated pigs are summarized in Table 1.

In this respect, the 5 anatomic regions under study exhibited similar microscopic 
changes throughout the 10 aforementioned time intervals of tissue sampling. In particular, the typical histomorphological architecture of normal skeletal muscle tissue was observed at "time 0" (Figure 1), with myofiber shape-related changes consistent with atrophy ("angularity", "rounding", etc.) being the earliest microscopic alterations observed, one month after starting ripening process (Figure 2). In fact, at one month after "time 0 " as well as during the subsequent ripening stages, morphologic changes consistent with progressive atrophy, rhabdomyolysis and/or sarcoplasmic hyalinization of increasing magnitude, associated or not with myofiber cavitation and/or rupture, were seen affecting individual myofibers and/or groups of them. An apparent enlargement of peri-endomysial spaces was also observed in conjunction with the aforementioned findings, with the amplitude of peri-endomysial stroma exceeding even by $2-3$ times the normal one, as a consequence of the neighboring/surrounding myofiber atrophy (Figure 2). At its turn, the size of myofibers affected by such progressively increasing atrophy was frequently reduced to one half, if not even one third, of their regular dimensions. Furthermore, an apparent increase of peri-endomysial fibro-reticular stroma was simultaneously detected one month after starting ripening process (Figure 2), with an additional increase of such component being observed at 4 months from the beginning of the ripening process (Figure 3 ) and, progressively, also throughout its subsequent phases (Figures 4 and 5). The aforementioned stromal component occasionally showed a dyshomogeneous organization, with special emphasis on collagen fibers, additionally exhibiting a varying stromal tissue cellularity and vascularization (Figure 3). A focal, apparent increase of the adipose component was additionally observed at 12 months after starting ripening process as well as throughout its subsequent stages (Figure 4). Furthermore, starting from 8 months after "time 0 ", clear-cut evidence of an increasingly compact, dehydration-related, tissue structure was found, with the degree of muscle density/thickness becoming progressively more consistent from 12 months after the beginning of the ripening process onwards (Figures 4 and 5).

We also observed focal images of blood vessel wall "hypertrophy", associated or not with muscle tissue "metaplasia", the latter one referring to a percentually increased prevalence of adipose tissue. Finally, more or less prominent bacterial aggregates were occasionally detected in some of the herein investigated muscle tissue specimens, with no evidence of inflammatory lesions being found in any of them.

\section{Discussion and Conclusions}

To the best of our knowledge, very few studies have been focused on the light and/or ultrastructural microscopic features of raw ham (Córdoba et al., 1994; Monin et al., 1997; Larrea et al., 2007a), with only one of them having addressed the structural modifications of the sarcoplasmal protein matrix throughout raw ham's ripening (Larrea et al., 2007b).

In this respect, the herein reported microscopic changes, showing similarities with those previously described elsewhere (Larrea et al., 2007b), were mostly driven by dehydration, their "common denominator". This is especially true for the progressively increasing muscle tissue density ascribable to water loss - an "intrinsic feature" of the raw ham's ripening process (Monin et al., 1997), as also clearly shown by the significant weight loss (ranging from

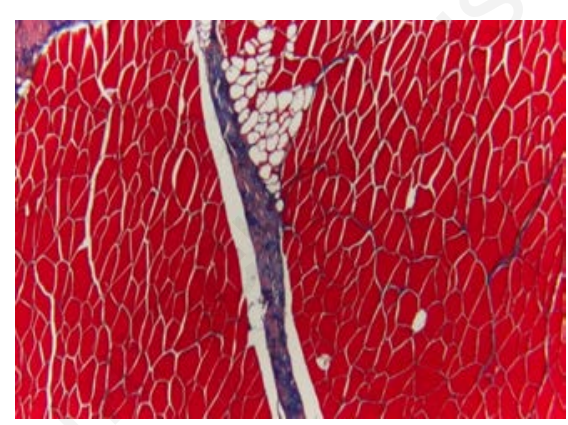

Figure 1. Raw ham ("time 0"). The microscopic architecture is fully reminiscent of that of normal muscle tissue. PicroMallory, x25 original magnification.

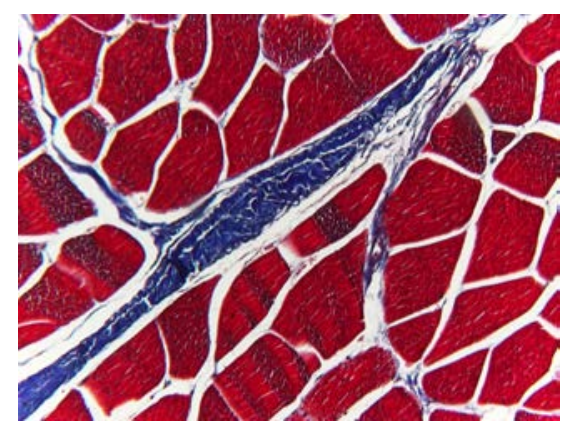

Figure 2. Raw ham (1 month after starting ripening process). Myofiber shape-related changes "'angularity" and, to a minor extent, also rounding) are shown, together with an apparent enlargement of periendomysial spaces as well as with an apparent increase of peri-endomysial fibro-reticular stroma. Picro-Mallory, x63 original magnification.
3.5 to $4.5 \mathrm{~kg}$ ) of the herein investigated raw hams from "time 0 " to the end of the ripening process. Within such context, dehydration should be regarded as a very plausible

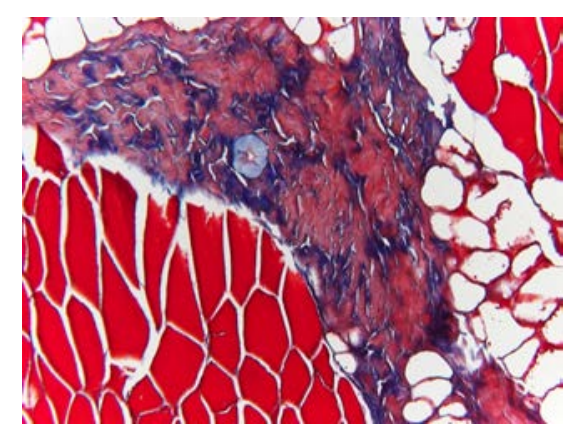

Figure 3. Raw ham (4 months after starting ripening process). An apparently more consistent peri-endomysial fibro-reticular stroma is shown, with such component also exhibiting a dyshomogeneous organization. Picro-Mallory, x63 original magnification.

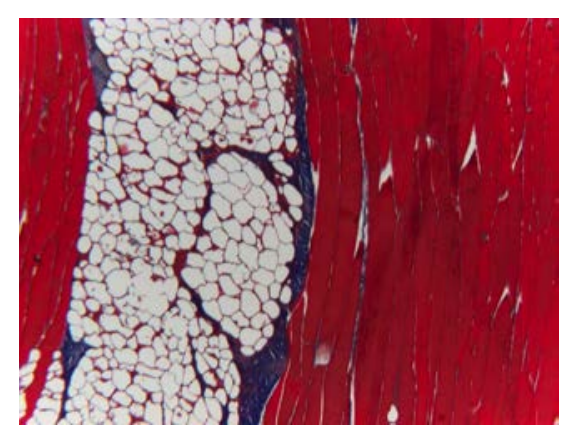

Figure 4. Raw ham (12 months after starting ripening process). A further, apparent increase of the peri-endomysial fibro-reticular stromal component is shown, coupled with a more pronounced muscle density/ thickness degree. A focal, apparent increase of the adipose tissue component is also observed. Picro-Mallory, x25 original magnification.

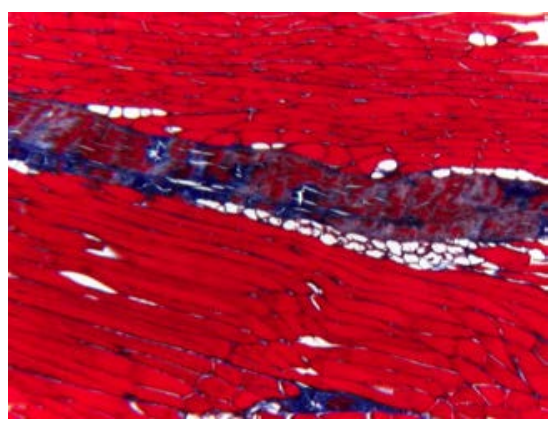

Figure 5. Raw ham (18 months after starting ripening process). A marked, dehydration-induced, muscle tissue density/thicknes is shown. Picro-Mallory, x25 original magnification. 
Table 1. Summary of the main microscopic findings observed in the raw ham samples under study in relation to different ripening stages (10 stages in total, from "time 0" up to 28 months after starting ripening process).

\begin{tabular}{|c|c|c|c|c|c|c|c|c|c|c|}
\hline & \multirow[b]{2}{*}{ Time 0} & \multirow[b]{2}{*}{$1 \mathrm{~m}$} & \multirow[b]{2}{*}{$3 \mathrm{~m}$} & \multirow[b]{2}{*}{$4 m$} & \multicolumn{6}{|c|}{ Ripening stage } \\
\hline & & & & & $8 \mathrm{~m}$ & $9 \mathrm{~m}$ & $12 \mathrm{~m}$ & $17 \mathrm{~m}$ & $23 \mathrm{~m}$ & $28 \mathrm{~m}$ \\
\hline Myofiber shape-related changes ("angularity", cell rounding, etc) & - & + & + & + & ++ & ++ & +++ & ++ & ++ & +++ \\
\hline Myofiber cavitation and/or rupture & - & - & - & + & ++ & ++ & - & ++ & + & ++ \\
\hline Myofiber rhabdomyolysis/hyalinization & - & + & + & + & ++ & ++ & + & ++ & +++ & +++ \\
\hline Adipose tissue component & - & - & + & + & + & + & ++ & ++ & ++ & ++ \\
\hline Dehydration-related changes (muscle tissue density/thickness) & - & - & + & + & ++ & ++ & +++ & +++ & +++ & +++ \\
\hline Peri-endomisial stromal component & - & + & + & ++ & ++ & ++ & +++ & +++ & +++ & +++ \\
\hline Peri-endomisial spaces' enlargement & - & + & + & + & - & - & + & ++ & ++ & ++ \\
\hline Bacterial aggregates & - & - & - & ++ & - & - & - & + & +++ & ++ \\
\hline Vessel wall hypertrophy & - & - & - & - & - & - & - & - & ++ & ++ \\
\hline Focal "metaplasia" & - & - & - & - & - & - & - & + & - & - \\
\hline
\end{tabular}

m, months. + modifications of light-small intensity/degree; ++ modifications of moderate-medium intensity/degree; +++ modifications of severe intensity/degree.

explanatory basis also for the apparent thickening of the peri-endomysial stroma, where degenerated myofibers and/or myofiber components may additionally accumulate throughout the ripening process, similarly to the focal, apparent increase of the adipose tissue matrix. Furthermore, the earliest histomorphologic changes herein described, such as myofiber "angularity" and/or "rounding", most likely represented the consequence of oxygen and nutrient deprivation, thereby resulting, at its turn, in a progressively increasing myofiber atrophy. These atrophic changes, affecting either individual or more or less numerous groups of myofibers, should be also regarded as a very plausible basis for the apparent, simultaneously detected enlargement of the neighboring/surrounding peri-endomysial spaces. Within such context, the herein described microscopic changes consistent with rhabdomyolysis, sarcoplasmic hyalinization, myofiber cavitation and/or rupture could have resulted from the proteolytic phenomena taking place during raw ham's ripening, with special emphasis on its most advanced stages (Toldrá and Flores, 1998; Larrea et al., 2007b).

Finally, as far as concerns the bacterial aggregates occasionally observed by us, they should be regarded as a normal and common finding in raw hams, as previously reported elsewhere (Chizzolini et al., 1993).

In conclusion, although this study was performed on raw hams from a given geographical area of Central Italy, coupled with the possibility that similar products from other Regions (Comi et al., 2009; Paleari and Beretta, 2011) might behave differently, we believe that the characterization of raw ham's microscopic features throughout the "physiological" ripening process may still represent a valuable aid also for a better definition, in conjunction with other analyses and parameters, of a number of alterations/defects which may affect the proper texture and the characteristic flavor of this Italian "flagship product".

\section{References}

Chizzolini R, Rosa P, Novelli E, 1993. Biochemical and microbiological events of Parma ham production technology. Microbiologia 9:26-34.

Comi G, Iacumin L, Tonizzo A, Cosatto $\mathrm{P}$, Zin J, Cichetti ME, Zuccolo CG, 2009. Shelf-life of San Daniele ham sliced and packed in MAP. Ind Alim 493:9-22.

Córdoba JJ, Antequera T, Ventanas J, López-Bote C, García C, Asensio MA, 1994. Hydrolysis and loss of extractibility of proteins during ripening of Iberian Ham. Meat Sci 37:217-27.

Fritz JD, Greaser ML, 1991. Changes in titin and nebulin in postmortem bovine muscle revealed by gel electrophoresis, western blotting and immunofluorescence microscopy. J Food Sci 56:60715.

Fritz JD, Mitchell MC, Marsh BB, Greaser ML, 1993. Titin content of beef in relation to tenderness. Meat Sci 33:41-50.
Gil M, Guerrero L, Sárraga C, 1999. The effect of meat quality, salt and ageing time on biochemical parameters of drycured Longissimus dorsi muscle. Meat Sci 51:329-37.

Larrea V, Hernando I, Quiles A, Lluch MA, Pérez-Munuera I, 2006. Changes in proteins during Teruel dry-cured ham processing. Meat Sci 74:586-93.

Larrea V, Pérez-Munuera I, Hernando I, Quiles A, Lluch MA, 2007a. Chemical and structural changes in lipids during the ripening of Teruel dry-cured ham. Food Chem 101:1327-36.

Larrea V, Pérez-Munuera I, Hernando I, Quiles A, Llorca E, Lluch MA, 2007b. Microstructural changes in Teruel drycured ham during processing. Meat Sci 76:574-82.

Monin G, Marinova P, Talmant A, Martín JF, Cornet M, Lanore D, Grasso F, 1997. Chemical and structural changes in dry-cured hams (Bayones Hams) during processing and effects of the dehairing technique. Meat Sci 47:29-47.

Paleari MA, Beretta G, 2011. Panoramica sulla produzione di prosciutti crudi tra $i$ più diffusi del mercato italiano. Ind Alim 512:17-23.

Toldrá F, Aristoy MC, 1993. Availability of essential amino acids in dry-cured ham. Int J Food Sci Nutr 44:215-19.

Toldrá F, Flores M, 1998. The role of muscle proteases and lipases in flavor development during the processing of dry-cured ham. Crit Rev Food Sci 38:331-52. 